\title{
REFLETINDO SOBRE REDES SOCIAIS DIGITAIS COM JOVENS NAS AULAS DE ARTES
}

Reflecting about digital social network with young people in art classes

\author{
João Alberto Rodrigues ${ }^{1}$
}

\begin{abstract}
${ }^{1}$ Mestre em Educação pela Faculdade de Educação da Universidade Federal do Rio Grande do Sul (Bolsista CAPES). Acadêmico de Especialização em Políticas Públicas e Gestão da Educação pela mesma instituição. Licenciado e Bacharel em Artes Visuais pelo Instituto de Artes da Universidade Federal do Rio Grande do Sul. Professor de Artes na Rede Estadual de Educação do Rio Grande do Sul em Porto Alegre.E-mail: ja.rodrigues@hotmail.com.br
\end{abstract}

Data do recebimento: 07/05/2020 - Data do aceite: 14/10/2020

RESUMO: Este trabalho se propõe a refletir de que maneira jovens estudantes percebem as redes sociais digitais e como estas operam mudanças em nossas relações. Neste artigo apresento reflexões advindas de um projeto para as aulas de artes com turmas de $9^{\circ}$ ano do Ensino Fundamental, de cerca de 15 e 16 anos, de uma escola estadual da rede pública do Rio Grande do Sul - Porto Alegre, em 2017 e 2018, na qual trabalhei. O estudo pautou-se pelas percepções desses estudantes em relação às redes, mediante conversas, trabalhos poéticos e leituras. Foi proposto como uma pesquisa-intervenção, a partir das referências de autoras como Laura Barros (2015) e Virginia Kastrup (2015). Para refletir sobre as múltiplas performances que circulam pelas redes, suas telas e imagens, busquei embasamento em teóricos como Byung-Chul Han (2016; 2017), Guy Debord (1997), Paula Sibilia (2016), Zygmunt Bauman (2011), dentre outros. No decorrer, apresento trabalhos poéticos realizados em aula, com os quais estabeleço relações teóricas. Este estudo realizado com jovens permitiu ver um conjunto de indícios e situações referentes às nossas relações mediadas pelas redes. Por fim, o presente artigo pretende ser uma ferramenta para ampliar os modos de relacionamento e a compreensão de jovens estudantes.

Palavras-chave: Jovens. Redes sociais digitais. Ensino de Artes Visuais. Performance social. 
ABSTRACT: This work aims to reflect on how young students perceive digital social networks and how they cause changes in our relationships. In this article reflections arising from a project conducted on the art classes with 9th grade groups of Elementary School, mean age around 15 to 16 years old from a public school in the state of Rio Grande do Sul, in Porto Alegre city, in 2017 and 2018, where the researcher worked. The study was guided by the perceptions of these students in relation to the networks, through conversations, poetic works and readings, during art classes. An intervention-research, based on researchers such as Laura Barros (2015) and Virginia Kastrup (2015) was proposed. In order to reflect on the multiple performances that circulate through networks, their screens and images, support from theorists such as Byung-Chul Han (2016; 2017), Guy Debord (1997), Paula Sibilia (2016) and Zygmunt Bauman (2011), among others was sought. During the course, poetic works created in class were presented, with which theoretical relationships were established. This study carried out with young people allowed to see a set of evidences and situations regarding relationships mediated by the networks. Finally, this article aims to be a tool to expand the relationship and understanding of young students.

Keywords: Young people. Digital social networks. Visual Arts Education. Social Performance.

\section{Introdução}

Este trabalho foi resultado de meus estudos de mestrado como professor-pesquisador combinado à minha prática pedagógica em artes em uma escola estadual de ensino fundamental em Porto Alegre, Rio Grande do Sul. Em 2017 e 2018, elaborei um projeto pedagógico para as aulas de artes com duas turmas de $9^{\circ}$ ano, com estudantes entre $15 \mathrm{e}$ 16 anos, com duração de 10 semanas, com os objetivos de acompanhar e refletir junto com eles/as ${ }^{1}$ sobre as múltiplas maneiras de se construir e se relacionar nas, pelas e com as redes sociais digitais, bem como, investigar suas sensibilidades, percepções e interpretações. Nessa etapa, meu interesse foi a realização de uma pesquisa-intervenção, já em função das aproximações entre pesquisador e campo.
Incomodavam-me as diversas e repetitivas falas e escritos que circulavam e circulam pelas escolas entre docentes, nas várias reportagens na mídia e até entre familiares, onde coloca-se que jovens, principalmente, ao ficarem cada vez mais online, acabam tornando-se mais passivos e dependentes.

O projeto teve duas etapas: a primeira, voltada para uma sensibilização crítica, aproximações e distanciamentos, selecionei uma gama de materiais para discutirmos nas aulas: imagens diversas, vídeos, charges, textos e propagandas, para exercitarmos tensionamentos entre nós, em relação à maneira como percebíamos algumas falas, gestos e práticas que circulavam em função das redes sociais digitais. E a segunda, a criação de trabalhos poético-visuais e produções textuais articuladas aos seus trabalhos produzidos.

Estes trabalhos poéticos e textos, assim como as falas das turmas durante as discussões e o processo criativo, tornaram-se o 
fio condutor de minha pesquisa, apontando caminhos. Busquei aproximar os trabalhos feitos por estudantes a algumas discussões teóricas com as quais percebia relações, exercitando, quando possível, observar as imagens, para tentar ver contradições e outras questões que suas falas e escritas não davam a entender, escapando.

Sendo a escola tanto meu local de trabalho quanto campo de pesquisa, busquei prestar atenção e aceitar o estranhamento. Tanto a etnografia quanto a cartografia foram ferramentas importantes para o desenvolvimento metodológico. Logo, tentei manter uma postura de quem estranhava falas, gestos e ações. Luciana Caldas ao tratar desse estranhamento, ressalta a experiência como abertura para o outro, ao desconhecido, para assim "apresentar o familiar em sua singularidade" (2016, p. 30).

De maneira semelhante, a pesquisadora Maria de Nazareth Hassen, escreve sobre a importância da etnografia na pesquisa em educação, colocando que esta "ambiciona fazer o leitor pensar: 'eu já vi isso, eu conheço isso, mas eu nunca tinha pensado que significasse isso ou que desse margem a essa interpretação"” (2018, p. 5, grifo da autora).

Quanto ao método cartográfico, há semelhanças com a etnografia, apontadas pelas pesquisadoras Laura Barros e Virgínia Kastrup (2015, p. 58), sobretudo pela valorização do lugar, das pessoas envolvidas, processos e na produção de subjetividades.

A partir dessas considerações, este estudo privilegia uma coesão entre pesquisa e intervenção. Eduardo Passos e Regina Barros (2015, p. 17) salientam que toda pesquisa é intervenção, porque, ao mergulhar no campo, produzimos efeitos nas pessoas com quem atuamos, em quem pesquisa, sobre as pessoas pesquisadas e até sobre os resultados nos quais chegamos. A pesquisa, sempre afeta de alguma maneira, as pessoas e o contexto.
A aproximação com a etnografia e o método cartográfico, foi providencial para orientar essa experiência de estar nesse lugar de convívio quase diário, no qual pude olhar, ouvir e conversar; buscando não naturalizar o que via e ouvia. E ao estar nessa posição que estranha os discursos que permeiam a escola, procurei construir junto desses/as jovens, imagens e narrativas diferentes daquelas que constituem nosso cotidiano, nas suas relações com as redes sociais.

\section{Quem elou o que mostramos?}

Com as múltiplas relações que estabelecemos com e pelas redes sociais digitais, como tais ferramentas passam a colaborar com nossas construções subjetivas e nas maneiras como nos relacionamos com as pessoas, nós mesmos/as e o mundo? Questionamentos do tipo levaram-me a pensar sobre como o ensino de artes no espaço escolar poderia colaborar na problematização de discursos e imagens cristalizadas e cristalizadoras de jovens. Apresentarei alguns trabalhos realizados durante as aulas, falas e escritas e as reflexões as quais me levaram, quando trabalhamos a questão da publicização de nossas vidas - exposição de corpos em si, atividades e situações cotidianas.

Em uma charge (Figura 1), um estudante desenhou um confessionário transformado em megafone pelo Facebook. O estudante tentou nos mostrar imageticamente o hábito de confessar elementos da vida íntima no espaço virtual, de uma abertura quase pública, em que se tem pouco controle sobre quem pode vir a ver mesmo com restrições. Um problema com esta imagem é que se trata de uma cópia de um trabalho do artista polaco Pawel Kuczynski. Desconhecia tal trabalho e o artista não estava presente no material que apresentei em aula. Assim, este estudante fez algo que provavelmente não considerou 
errado, pois em um ambiente digital onde as imagens circulam de forma intensa e são consumidas, geralmente, sem terem suas fontes e ou autorias conferidas, esta era só mais uma imagem. E cabe a observação sobre o quão difícil é as vezes evitar que copiem, não apenas pelo fato da cópia ser uma prática comum na escola, mas porque muitas vezes, há estudantes que acreditam não ter criatividade ou capacidade para criar, ou que consideram isso muito trabalhoso. Assim o trabalho docente de estimular a experimentação e a criação pode falhar em reduzir tais bloqueios, a crença de que não é capaz de fazer ou que este é o caminho mais fácil. Assim, faz-se importante também mostrar o que não consegui fazer como professor.

Figura 1 - Lápis colorido sobre papel, 29 x 40 cm, 2018

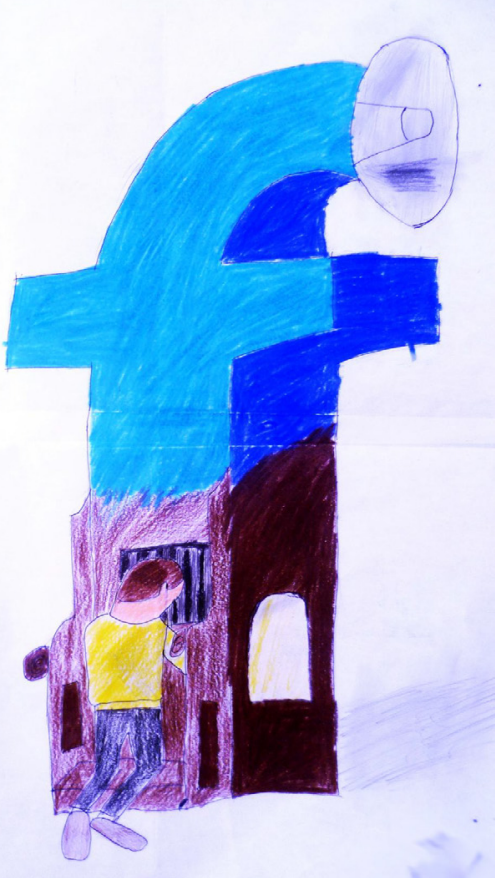

Mas tal imagem também nos lembra da característica nebulosa entre o que seria o espaço privado e o público, pois na atualidade ambos se misturam em muitos contextos, ficando em constante intersecção. $\mathrm{O}$ pes- quisador Cleber Ratto (2006, p. 28) avalia o fato de que, as técnicas de comunicação nunca interferiram tanto sobre nossas existências, havendo uma quase naturalidade, pela sua ubiquidade. Por outro lado, Paula Sibilia (2016) chamou de "diário éxtimo", um diário virtual de exposição da intimidade praticamente público.

Ainda, próximo desse conceito de extimidade, Cleber Ratto (2006, p. 33) considera o surgimento de uma "intimização assistida", uma maneira de se expor. Considerada assistida, por ter a valorização e manutenção da intimidade ligada a uma apresentação pública.

Nesse contexto, tanto a produção da extimidade, apontada por Sibilia (2016), bem como a "intimização assistida", de Ratto, poderiam ser compreendidas a partir do pensamento do filósofo Byung-Chul Han (2017) que escreve sobre o fenômeno da transparência em nossa sociedade, resultante de mudanças tecnológicas, que afetam outros aspectos da vida. Esta transparência desembocaria em uma sociedade positiva, que foi ganhando forma durante o século XX, em que tudo se busca mostrar, nivelar e comunicar, desfazendo uma forma anterior, chamada de sociedade da negatividade, na qual haveria espaços para o não comunicável, o mistério.

Uma característica nos trabalhos estudantis foi a busca por likes e a vontade de atrair a atenção de outras pessoas, algo que diversos/ as estudantes consideravam exagerado, como uma tentativa de ser outra pessoa ou viver de aparências. A ideia da máscara apareceu em alguns trabalhos. Em outras palavras, nas conversas e nos próprios trabalhos em aula, estávamos, em diferentes momentos, tangenciando a discussão sobre real e virtual.

No tocante à essa discussão sobre aparências no âmbito virtual, também, pode-se destacar a lógica da competitividade, alimentada pela popularidade e o consumismo. A 
mesma autora, Sibilia (2016, p. 42) aponta que muitas pessoas desenvolvem "estratégias pessoais de exibição nas telas" como se fosse algo natural. Mas salienta que não é qualquer tipo de imagem, são cenas da vida cotidiana a serem exibidas. Faz parte desse ritual, um cuidado na escolha do que será exibido: a curadoria de uma vida tornada imagem de forma online, em que enfatizar, hierarquizar, apagar, cortar e escolher são ações estratégicas (SIBILIA, 2016, p. 42). E ao tornar-se editável, fica a sensação de que se pode apagar e recomeçar, quando for necessário.

E ao nos tornarmos imagens digitais, acabamos por usar certas regras de visibilidade pública, concebendo uma imagem pública e, neste caso, não como a "representação tecnicamente audiovisual (retrato, filme, etc) de um referente humano, mas um simulacro verossímil ou crível" (SODRÉ, 2002, p. 37).

No desenho (Figura 2), a estudante mostra concepções de felicidade e falsidade, sentimentos que já chamavam sua atenção em várias ocasiões nas aulas. A parte colorida, como escreveu em seu texto, seria uma felicidade sem medidas, ao lado, o contraste em tons cinzentos, a realidade ou a vida cotidiana.
Figura 2 - Lápis colorido e grafite sobre papel, 59 x 42 cm, 2018

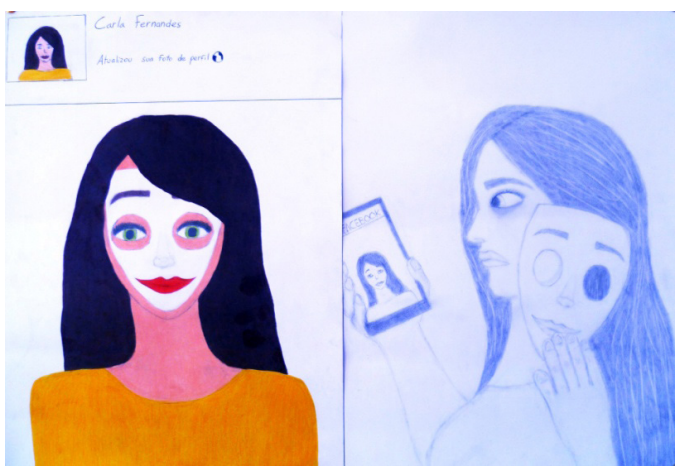

A estudante também verbalizava como se houvesse duas realidades, real e virtual, permanecendo a primeira escondida por trás da segunda: "a intenção de mostrar uma realidade até mesmo escondida de muitos", como é possível lermos no fragmento de sua redação (Figura 3).

Em seus depoimentos era muito presente um comentário sobre o cotidiano, sobre a demarcação entre o que seria a realidade e o que não seria, sendo o virtual, associado ao falso. Não pretendi aprofundar tal questão neste trabalho, o que demoraria, mas apenas aproximo-me de uma breve reflexão da professora Nadja Hermmann (2005, p. 36) quanto a isso, problematizando a questão, ela

Figura 3 - Fragmento de produção textual, 2018

Essse trabatho tem a intenzeà de mastras unsa realidade até metma escondida de mentas, claro, que en tades latat mä precita sen necettíriamente astim, a rede tocial coma jor dy is nome, í futa para nás sovinlizarmas iam o outro, e nào uma rede de propugrinda, ande mastram eaisas denciet, tudo demies, apenat para ser mastrado e comentads. Nos preitamal saber war ina perramenta com taledaria 1 maderaféto. 
fala sobre a porosidade existente entre realidade e virtualidade. Em contextos imersos em diferentes tipos de mídias, estas colaboram na construção do que chamamos realidade e não como uma face oposta ou falsa desta; o virtual passou a ser realidade, uma referência "concreta" da mesma.

Um grupo de meninos fez uma série de máscaras de gesso e, entre esses resultados uma era mais próxima de um rosto humano, a ideia era abordar o que mostramos e o que escondemos (Figuras 4 e 5).

Figura 4 - Monitor e gesso, dimensões diversas, 2018

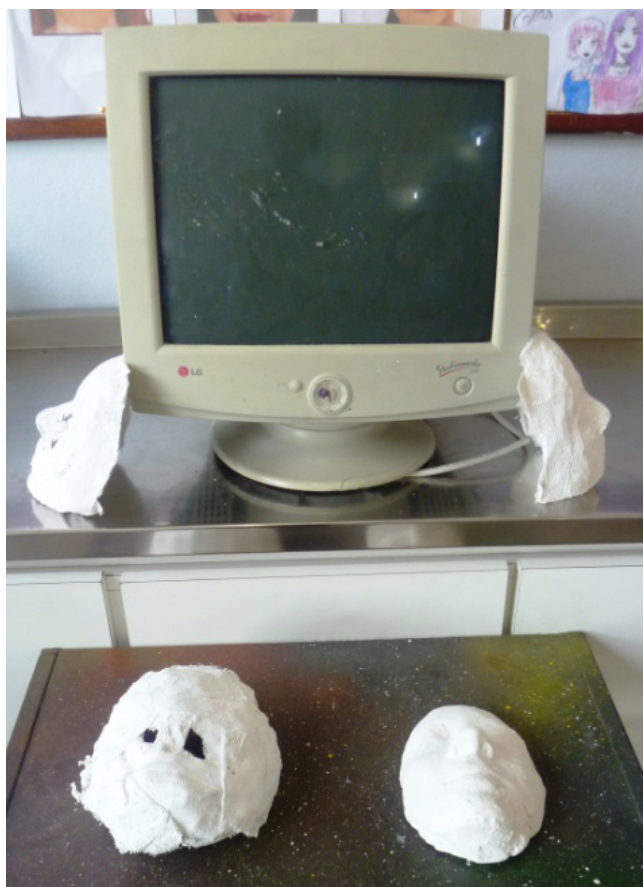

Figura 5 - Detalhe, 2018

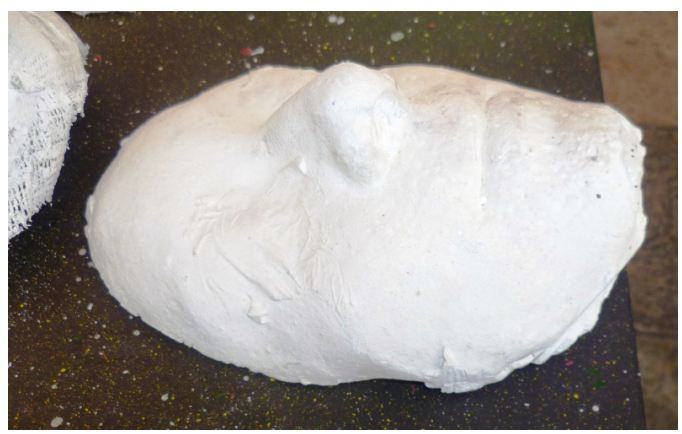

Guy Debord (1997, p. 18) apontou que com a predominância do econômico sobre a vida social, ocorreria uma degradação do ser, reduzido ao ter. No século XIX e início do XX, o acúmulo de bens diversos (considerados de bom gosto) poderiam definir o que o ser humano era (SIBILIA, 2016). Mas atualmente, ocorreu a valorização do parecer sobre o ter. "Se não se mostra, se não aparecer à vista de todos e os outros não o veem, então, de pouco servirá ter seja lá o que for. Agora, portanto, o importante é parecer" (SIBILIA, 2016 , p. 122, grifo da autora). Consequentemente, verbos como guardar e acumular enfraquecer-se-iam, sendo substituídos por outros, como parecer e acessar, assim como pelos substantivos aparência e visibilidade. Neste contexto, segundo Debord (1997, p. 17), surgiu um raciocínio tautológico simples, no qual o que aparece é bom, e o que é bom aparece, o que nos conduziria a uma predominância do que apresentamos. A definição do autor de espetáculo não considerava apenas um mero agrupamento de imagens e sim uma "relação entre pessoas, mediada por imagens" (DEBORD, 1997, p. 14). No contexto de parte de uma sociedade marcada pelas redes sociais digitais, essa característica intensificou-se e intensifica-se cada vez mais.

Em meio a esse contexto de competitividade e exibição, é importante pensarmos algumas características de estados emocionais como satisfação e insatisfação a respeito de si mesmo. O psicanalista Jurandir Costa (2004, p. 151) escreve que a insatisfação é o desapontamento resultante do distanciamento entre a satisfação esperada e a alcançada. Enquanto a satisfação é alimentada pela relembrança de experiências passadas, nas quais se atingiu a coisa almejada, assim, também a satisfação é a realização plena dos objetivos, o prazer ao qual se chega com isso.

Ainda para o mesmo autor, é possível relacionar a insatisfação (ou sua eventual possibilidade), com a insatisfação dos em- 
penhos de muitas pessoas pela aparência; o que contribuiria para ao desenvolvimento de certa hipersensibilidade em relação a características consideradas problemas na imagem corporal, nos levando a sentir algumas vezes, uma insegurança frente a comentários sobre nossa aparência física (COSTA, 2004, p. 199).

\section{Performances nas telas}

Costa (2004, p.197) destaca o fato de precisarmos do reconhecimento de outras pessoas para ficarmos seguros do valor de nossos ideais de eu. Tal situação poderia levar-nos a desprezar outra pessoa próxima como alguém que nos avalia (por não a reconhecermos como alguém capaz) e consequentemente idealizarmos pessoas distantes, (des)conhecidas, virtuais, e que possivelmente nem sabem de nossa existência. Ao acreditarmos que existe um outro invisível nos admirando, reconhecendo e sendo até influenciado por nossos gestos, cabe perguntarmo-nos, quantos outros distantes, virtuais e invisíveis imaginamos nos olhando? Mesmo com dúvidas, o quanto apostamos ser possuidores da admiração desse outro imaginado ou imaginário, ao colocarmos uma fotografia em uma rede social digital? E seria isso o suficiente, independente das repercussões, para continuar postando e almejando a admiração desses outros? Em parte, refletir sobre os comportamentos na adolescência e juventude, passa por esses questionamentos.

Essa busca por acumular likes proporcionalmente desejável ao exposto é algo que motiva muitas pessoas a colocarem seus registros. Isso provoca uma série de outras ações, como as trocas de favores e, por exemplo, correntes virtuais, tais como uma curtida por uma curtida.

Sibilia (2016, p. 43) lembra que, para aumentar a competitividade virtual, há criações de contas falsas até compra de likes em sites. Agradar e ser agradado é indispensável, porque com likes estabelecemos conexões e comunicações de maneira mais veloz do que com dislikes (HAN, 2017, p. 24), logo, o que foi exposto na rede, pode ganhar um "atestado de qualidade".

Associo essa característica das curtidas nas imagens, ao que o psicanalista Antônio Quinet (2004) chama de poder da imagem, uma sensação de captação e fascinação que levaria a pessoa que olha a identificar-se com o que está olhando. É possível aproximar o conceito do autor ao contexto das redes sociais, uma pessoa pode acreditar que, ao curtir uma imagem, ela será afetada positivamente por isso, porque, ao identificar-se com a imagem postada, poderia se aproximar do sucesso que aquela imagem/pessoa obteve, obtém ou obterá.

Uma imagem que provoca e sintetiza bem a busca por agradar e obter likes com regularidade, seria a escultura construída por um estudante (Figura 6) que escreveu que com isso, as pessoas também acabam por não se

Figura 6 - Isopor, caixa de papel e tigela, $40 \times 30 \times 20 \mathrm{~cm}$ aproximadamente, 2017

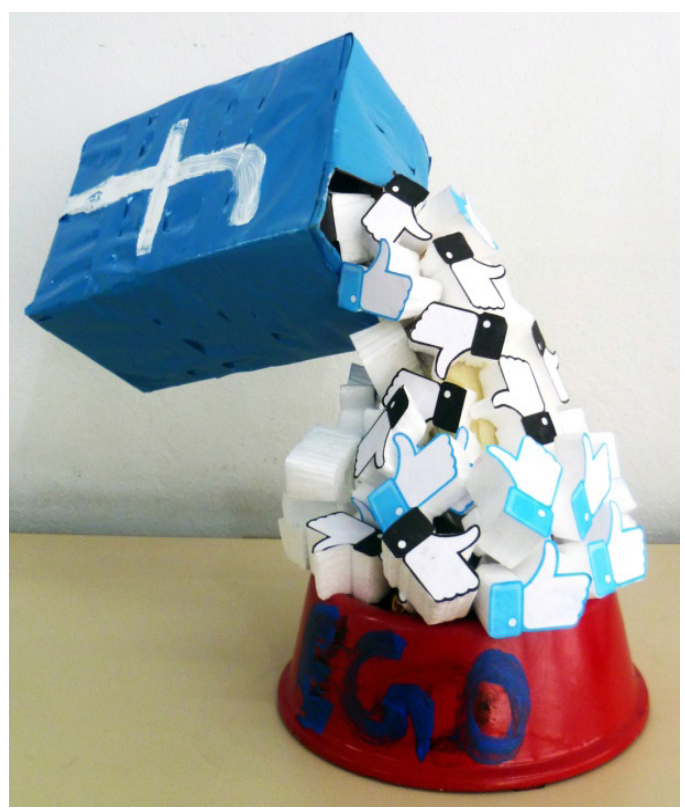




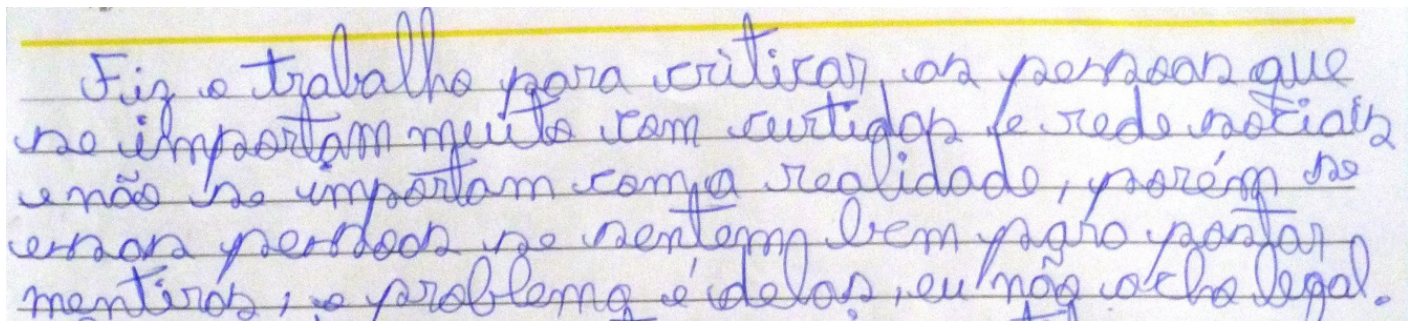

importar com a realidade (Figura 7). Mas nesta escultura temos novamente uma cópia, como foi com a Figura 1, de parte de uma ilustração do artista inglês John Holcroft, que também não foi apresentado às turmas. $\mathrm{E}$ assim como o anterior, este também não falou que estava copiando, nem que inicialmente gostaria de basear-se em algum trabalho existente ou até que pretendia fazer uma releitura.

\section{Usos desmedidos e uma possível solidão(?)}

Quando pensamos no uso das redes sociais digitais por adolescentes e jovens, os modelos de passividade, atraem facilmente. Um imaginário que pode ser ou não partilhado apenas por pessoas adultas. No entanto, houve estudantes que decidiram trabalhar com essa ideia, de uma relação que beira(ria) o vício. Duas estudantes falaram disso ao usarem imagens de seringas em seu trabalho (Figura 8). Nessa representação, que permite uma associação direta com drogas, assim como de alguma coisa que precisa ser usada com regularidade, tendo em vista as nossas necessidades e demandas.

Embora as alunas terem pensado em criticar um possível vício, houve um desencontro entre as próprias práticas cotidianas quanto ao uso intensivo das mídias sociais e dos celulares e a intenção de operar um julgamento moral sobre outras pessoas.
Figura 8 - Seringas e corante, cerca de $3 \times 16 \times 3 \mathrm{~cm}, 2017$

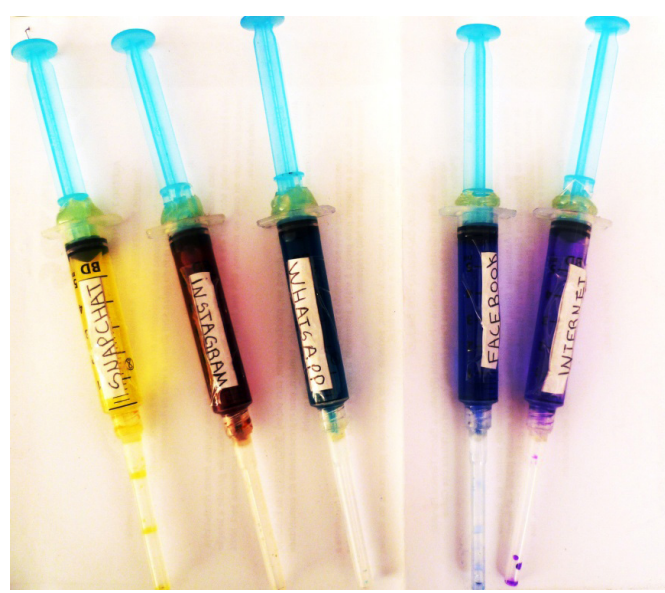

Em um diálogo com o sociólogo Zygmund Bauman (2011), que relacionou as crises de abstinência de jovens que usam drogas com a agonia daqueles que acabam sendo desconectados, pela ação de familiares responsáveis ou pela escola. Essas associações e a metáfora cotidiana que movimentou o trabalho dessas meninas, é outra dessas imagens que nos atravessa.

Uma dupla de meninos fez uma escultura (Figura 9) para abordar o hábito das pessoas filmarem tudo e estarem constantemente com os celulares nas mãos, nos mais variados lugares e situações. Ainda que eles mesmos estivessem quase sempre segurando os celulares. O que essa peça revela? Poderíamos pensar numa possível extensão do corpo, num objeto de desejo e num sujeito, unidos permanentemente no gesso? E que imaginário tal peça abriga? 
Figura 9 - Gesso, cerca de 20 × 25 × $25 \mathrm{~cm}, 2018$

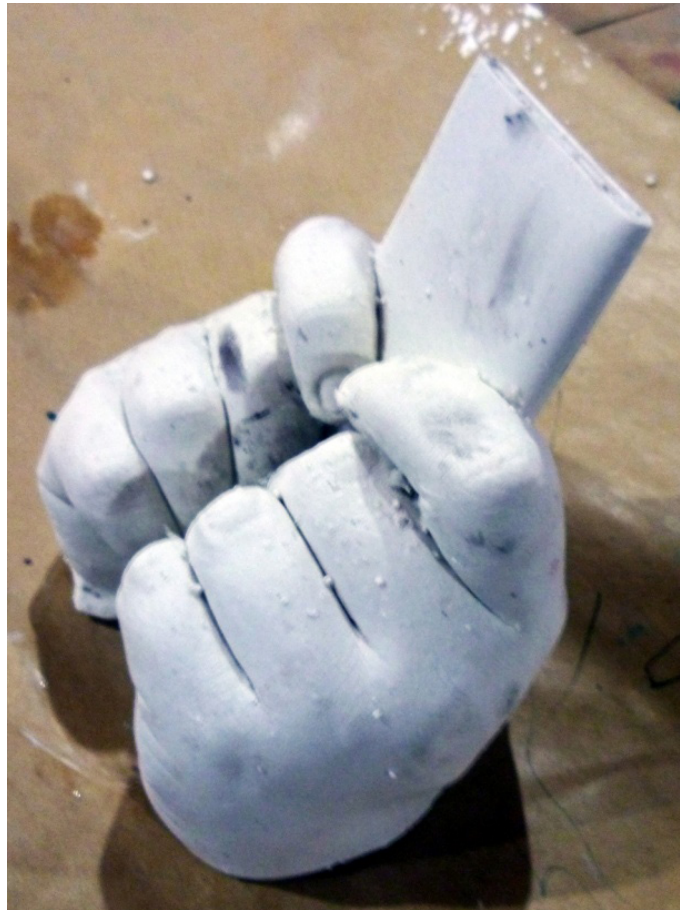

Outra preocupação exposta pelos estudantes foi em relação ao tempo e a qualidade de diálogo, a percepção do pouco valor dado a essa relação pessoal e sem a mediação de telas. Talvez entre essas/es estudantes houvesse quem realmente se incomodasse com isso, contraditoriamente ou não, alguns preferiam digitar a falar pelo celular. Muito provavelmente pela abertura à edição que esse formato de conversa possibilita, assim como um outro tempo de resposta. Tal percepção seria mais uma das tantas sedimentadas ao longo do tempo em nós?

Debord (1997, p. 189) vaticina que a conversação estaria em vias de desaparecimento e em pouco tempo, os que saberiam falar estariam mortos. Esses pensamentos seguiriam à condição atual da comunicação interpessoal, tal como Bauman (2011) escreveu que, com o advento das redes sociais digitais, criou-se a possibilidade de iniciarmos a qualquer momento e encerrarmos uma conversa perigosa e indesejável, sem quaisquer exigências.

Em outro desenho (Figura 10), uma estudante colocou múltiplas situações cotidianas em relação às redes sociais e escreveu que embora nos aproximem de quem está longe, acabam por nos afastar de quem está perto.

Figura 10 - Lápis colorido e impressões sobre papel, 59 x $42 \mathrm{~cm}, 2018$

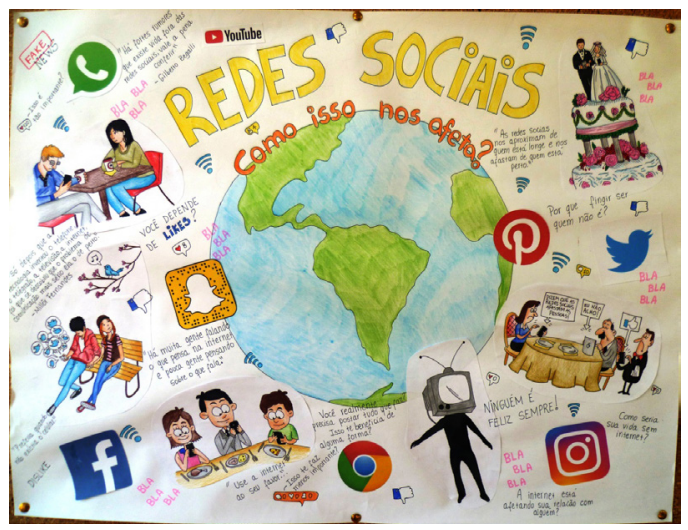

Ela escreveu (Figuras 11 e 12) "que tudo tem um limite e que devemos ter consciência do quanto isso nos afeta." Em meio a isso, ela nos diz que estaríamos frente a um instrumento perigoso: "o mundo todo, sem exceções, está propenso a cair nessa armadilha se não tiver cuidado.” O “cair”, estaria

Figura 11 - Fragmento de produção textual, 2018 


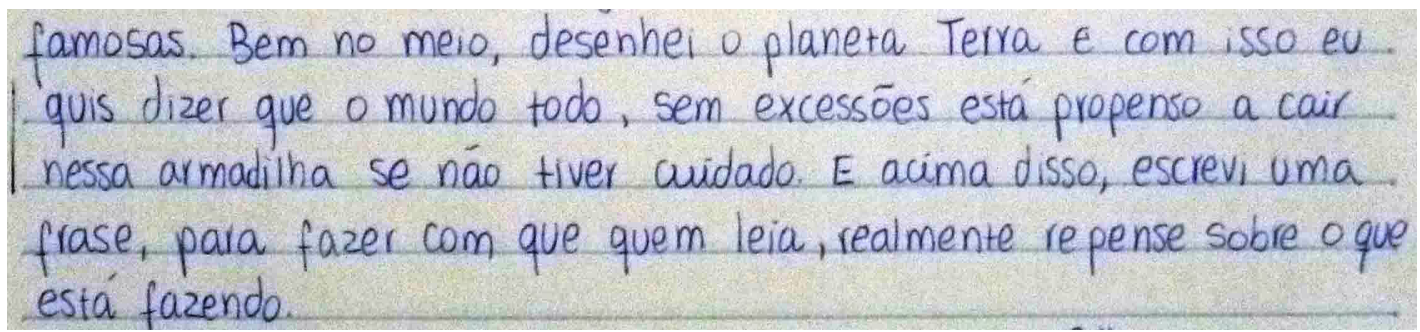

ligado ao tempo prolongado que muitos de nós passamos nas redes e ou relacionado às mudanças em nosso cotidiano?

Destaco o pensamento de Debord (1997) que se referiu à construção do isolamento, com os usos cotidianos do carro à televisão, assim como de outros bens, acabariam por serem ferramentas para uma constante manutenção do distanciamento entre pessoas, construindo de forma lenta o que denominou de multidões solitárias.

$\mathrm{Na}$ sua crítica, Debord apontou que o "espetáculo reúne o separado, mas o reúne como separado" (1997, p. 23). A maneira de funcionar dessa estrutura abarcaria locais de trabalho, moradias e espaços de lazer; isso nos levaria, em diferentes situações de espaço e tempo, a ficarmos distanciados. Esse contexto seria permeado por imagens de narrativas dominantes que enfraqueceriam os vínculos sociais entre as pessoas. (DEBORD, 1997, p. 114).

Nesse contexto, Bauman (2011) escrevera que, devido à instabilidade e insegurança de nossa época, ficar sozinho passou a ser percebido como um desconforto, mas os meios eletrônicos e digitais não eram os responsáveis por isso; eles apenas aumentaram uma necessidade já existente. Ele nos lembra da promessa associada ao walkman, de que as pessoas não ficariam mais sozinhas. Muitas pessoas, que cada vez menos desfrutavam da companhia de outras pessoas, obteriam o som ininterrupto para tentar preencher o vazio. Com o avanço das redes digitais e suas imagens, talvez esse vazio fora mascarado de maneira mais sofisticada. Em meio a isso, podemos nos perguntar se muitos e muitas de nós não estaríamos vivendo com fragmentos visuais e audiovisuais para ocupar esse vazio cotidiano.

Com Han (2016, p. 26), acrescento mais algumas palavras sobre a solidão, o filósofo considera a solidão que muitas pessoas vivem hoje, como resultante do declínio daquilo que era/é da ordem do comum e do comunitário. A fragilidade da ideia de público em diferentes partes da sociedade participaria de tal queda, colaborando no sentido da separação entre as pessoas, investindo suas energias majoritariamente no âmbito privado da individualidade.

Nessas argumentações, não estou retirando a importância das redes sociais digitais no nosso cotidiano, faço apenas uma ressalva: mesmo que mídias e redes sociais possam abrir o risco do afastamento, simultaneamente, aproximam pessoas, principalmente, em meio à correria ou limitações cotidianas, ainda mais em um contexto no qual o tempo torna-se um luxo para as pessoas.

\section{Considerações Finais}

Apresento algumas indagações, no que se refere à aparente dubiedade das manifestações de estudantes comentadas, quando provocados a falar de si e das maneiras como 
percebem e interpretam as suas relações e de outras pessoas com as redes digitais.

Outro aspecto importante que foi possível perceber em suas falas e escritas é o atravessamento feito por um discurso maior (da crítica às mídias e ao tempo dispendido diariamente) ficando em uma reprodução parcial. Talvez, tal ambiguidade seja a materialização de uma necessidade de ter uma postura crítica, mas sem reflexos quanto à própria maneira cotidiana de utilizar as redes sociais.

Por isso teríamos como resultados, produções e falas que não divergiriam muito das falas diárias e ouvidas por familiares e docentes, em casa e na escola, logo fazer o movimento por parte delas e deles de suspender isto e contornar, buscando outras percepções, interpretações e reflexões é difícil, mesmo com uma provocação momentânea para isso. E não caberia a mim, como professor, no caso de um assunto como as redes digitais, forçar uma outra percepção ou criação, só para sair um resultado diferente, que me agradasse. Este é um exercício válido para nós docentes: o de saber lidar com o que não dá certo, com o que não foi alcançado e refletir sobre isso para tirarmos algo.
Penso essas atitudes (aparentemente contraditórias) quanto ao tempo de uso das redes e de criticar esses modos, de forma interligada às construções narrativas sobre estudantes operadas no espaço escolar, em que uma mesma pessoa é autora, narradora e a personagem principal.

Quando falamos sobre nós, nossa ligação com outras histórias que nos constroem, permanecem, e consequentemente, falam sobre nós de certo modo. Logo, nossas concepções acerca de nós e de outras pessoas estariam enlaçadas a todos esses discursos. Tal reflexão pode nos ajudar a entender ou deixar menos confusas as diversas situações que envolvem as falas e práticas de jovens quanto aos usos das redes sociais.

Com o presente trabalho, não pretendi abordar caminhos para tratar os já tão falados problemas decorrentes das relações entre adolescentes e jovens com seus celulares na escola, pretendo apenas colaborar com docentes que queiram aproximar-se mais dos/as estudantes com que trabalham, em um exercício de tentar olhar, ouvir e entender. $\mathrm{O}$ exercício de buscar suspender os julgamentos rápidos tão tentadores e descristalizar essas imagens fáceis.

\section{NOTAS}

1 Os trabalhos apresentados não constam com os nomes de estudantes, assim como os mesmos não são identificados ao longo do texto.

\section{REFERÊNCIAS}

BARROS, L. P.; KASTRUP, V. Cartografar é acompanhar processos. In: ESCÓSSIA, L.; KASTRUP, V.; PASSOS, E. (org.). Pistas do método da cartografia: Pesquisa-intervenção e produção de subjetividade. Porto Alegre: Sulina, 2015. p. 52-75. 
BARROS, R. B.; PASSOS, E. A cartografia como método de pesquisa-intervenção. In: ESCÓSSIA, L; KASTRUP, V; PASSOS, E. (org.). Pistas do método da cartografia: Pesquisa-intervenção e produção de subjetividade. Porto Alegre: Sulina, 2015. p. 17-31.

BAUMAN, Z. 44 cartas do mundo líquido moderno. Disponível em: http://lelivros.love/book/ baixar-livro-44-cartas-do-mundo-liquido-moderno-zygmunt-bauman-em-pdf-epub-e-mobi/ Acesso em: 22 abr. 2020.

CALDAS, L. T. “Clube das 5”: transformação e criação de si em práticas cinematográficas no espaço escolar. 2016. 85 f. Dissertação (Mestrado em Educação) - Faculdade de Educação, Universidade Federal do Rio Grande do Sul, Porto Alegre, RS, 2016.

COSTA, J. F. O vestígio e a aura: corpo e consumismo na moral do espetáculo. Rio de Janeiro: Garamond, 2004.

DEBORD, G. A sociedade do espetáculo. Rio de Janeiro: Contraponto, 1997.

HAN, B. C. No enxame. Reflexões sobre o digital. Lisboa: Relógio D’Água Editores, 2016.

HAN, B. C. Sociedade da transparência. Petrópolis: Vozes, 2017.

HASSEN, M. N. A. Etnografia: noções que ajudam o diálogo entre antropologia e educação.

Disponível em: http://www.ufrgs.br/fotoetnografia/textos/metodologia_nazareth.pdf Acesso em: 22 abr. 2020.

HERMANN, N. Ética e estética: a relação quase esquecida. Porto Alegre: EDIPUCRS, 2005.

QUINET, A. Um olhar a mais - ver e ser visto na psicanálise. 2. ed. Rio de Janeiro: Jorge Zahar Ed., 2004.

RATTO, C. G. Compulsão à comunicação: modos de fazer falar de si. Educação \& Realidade, n. 2, v. 31, p. 27-42, 2006. Disponível em: https://seer.ufrgs.br/educacaoerealidade/article/ view/6843/4114. Acesso em: 22 abr. 2020.

SIBILIA, P. O show do eu - como espetáculo. 2. ed. Rio de Janeiro: Contraponto, 2016.

SODRÉ, M. Antropológica do espelho: uma teoria da comunicação linear e em rede. Petrópolis: Vozes, 2002. 